\title{
Aircraft millimeter-wave passive sensing of cloud liquid water and water vapor during VOCALS-REx
}

\author{
P. Zuidema ${ }^{1}$, D. Leon ${ }^{2}$, A. Pazmany ${ }^{3}$, and M. Cadeddu ${ }^{4}$ \\ ${ }^{1}$ Rosenstiel School of Marine and Atmospheric Sciences, University of Miami, Miami, Florida, USA \\ ${ }^{2}$ Department of Atmospheric Sciences, University of Wyoming, Laramie, Wyoming, USA \\ ${ }^{3}$ Prosensing Inc., Amherst, Massachusetts, USA \\ ${ }^{4}$ Argonne National Laboratory, Argonne, Illinois, USA
}

Correspondence to: P. Zuidema (pzuidema@rsmas.miami.edu)

Received: 2 July 2011 - Published in Atmos. Chem. Phys. Discuss.: 8 July 2011

Revised: 12 December 2011 - Accepted: 23 December 2011 - Published: 5 January 2012

\begin{abstract}
Routine liquid water path measurements and water vapor path are valuable for process studies of the cloudy marine boundary layer and for the assessment of large-scale models. The VOCALS Regional Experiment respected this goal by including a small, inexpensive, upwardpointing millimeter-wavelength passive radiometer on the fourteen research flights of the NCAR C-130 plane, the Gband $(183 \mathrm{GHz})$ Vapor Radiometer $(\mathrm{GVR})$. The radiometer permitted above-cloud retrievals of the free-tropospheric water vapor path (WVP). Retrieved free-tropospheric (abovecloud) water vapor paths possessed a strong longitudinal gradient, with off-shore values of one to two mm and nearcoastal values reaching ten $\mathrm{mm}$. The VOCALS-REx free troposphere was drier than that of previous years. Cloud liquid water paths (LWPs) were retrieved from the sub-cloud and cloudbase aircraft legs through a combination of the GVR, remotely-sensed cloud boundary information, and insitu thermodynamic data. The absolute (between-leg) and relative (within-leg) accuracy of the LWP retrievals at $1 \mathrm{~Hz}$ $(\sim 100 \mathrm{~m})$ resolution was estimated at $20 \mathrm{~g} \mathrm{~m}^{-2}$ and $3 \mathrm{~g} \mathrm{~m}^{-2}$ respectively for well-mixed conditions, and $25 \mathrm{~g} \mathrm{~m}^{-2}$ absolute uncertainty for decoupled conditions where the input WVP specification was more uncertain. Retrieved liquid water paths matched adiabatic values derived from coincident cloud thickness measurements exceedingly well. A significant contribution of the GVR dataset was the extended information on the thin clouds, with $62 \%(28 \%)$ of the retrieved LWPs $<100$ (40) $\mathrm{g} \mathrm{m}^{-2}$. Coastal LWPs values were lower than those offshore. For the four dedicated $20^{\circ} \mathrm{S}$ flights, the mean (median) coastal LWP was 67 (61) $\mathrm{g} \mathrm{m}^{-2}$, increasing to 166 (120) $\mathrm{g} \mathrm{m}^{-2} 1500 \mathrm{~km}$ offshore. The overall LWP
\end{abstract}

cloud fraction from thirteen research flights was $63 \%$, higher than that of adiabatic LWPs at $40 \%$, but lower than the lidardetermined cloud cover of $85 \%$, further testifying to the frequent occurrence of thin clouds.

\section{Introduction}

The VOCALS Regional Experiment, held in OctoberNovember 2008 in the southeast Pacific (SEP), had one focus on acquiring field measurements capable of illuminating the processes linking aerosols, clouds, and precipitation (Wood et al., 2011b), field measurements that could then help assess modeled cloud-aerosol interactions (e.g., Saide et al., 2011, and references therein). Cloud property datasets were also desired with which to assess large-scale climate models (Wood et al., 2011b). These considerations motivated the choice of instruments placed upon the NCAR C130 plane. These included not only in-situ aerosol and microphysical probes, but also cloud remote sensors that could routinely provide information on stratocumulus precipitation and its vertical profile, the cloud boundaries, and liquid water (Wood et al., 2011b). These choices, given finite aircraft space, recognized the value of airborne remote sensors for cloudy boundary layer studies (e.g., Vali et al., 1998; van Zanten et al., 2005; Rauber et al., 2007; Bretherton et al., 2010; Wood et al., 2011a; Wang et al., 2011). The National Science Foundation now includes a cloud radar and lidar in its deployment pool, and has invested in them for its newest airborne platform for environmental research. 
VOCALS-REx included the $94 \mathrm{GHz}$ (3.2 mm wavelength) Wyoming Cloud Radar (WCR) and the 355-nm wavelength Wyoming Cloud Lidar (WCL; Wang et al., 2009) on the C130 plane. The planners of VOCALS-REx also recognized the value of routine, ideally instantaneous, liquid water path (LWP) estimates. US aircraft missions have generally limited their use of microwave radiometry for boundary-layer cloud process studies, maybe because downward-looking radiometers need to account for surface reflectance and emission (e.g., Liu et al., 2003), or, because the instrument sizes can challenge payload restrictions. The search for a suitable radiometer ultimately led to a unique (for stratocumulus studies) feature of the VOCALS Regional Experiment: the inclusion of the millimeter-wave 183-GHz G-band Vapor Radiometer (GVR) (Pazmany, 2007) on the C-130 plane. The radiometer fit into a standard wing-mounted canister. Its small radiometer size is in part a virtue of its small wavelength $(\sim 1 \mathrm{~mm})$ compared to those from more standard microwave instruments $(\sim 10 \mathrm{~mm})$. An upward-pointing orientation facilitated integration with data from an upwardpointing radar and lidar, and allowed the retrievals to use the isotropically-emitting cold space as the boundary condition.

A surface-based version of the GVR was deployed at Barrow, Alaska (Racette et al., 2005; Pazmany, 2007; Cadeddu et al., 2007; Cimini et al., 2007, 2009), where the high sensitivity of $170-197 \mathrm{GHz}$ radiation to water vapor and liquid water emission within a cold, dry climate (WVPs $<5 \mathrm{~mm}$ ) could be used to full advantage. The airborne GVR has also been applied to wintertime mixed-phase clouds in the dry western United States (Wang et al., 2011). As shown later, the WVP values retrieved by the GVR for the freetroposphere of the southeast Pacific are similar to surface WVP values for Barrow, Alaska (see also the discussion of measurements from the Chilean altiplano in Turner and Mlawer, 2010). The low free-tropospheric WVP values reinforce the idea that a broad window in the infrared spectrum is available for stratocumulus cloud top radiative cooling in the southeast Pacific. The free-tropospheric WVP retrievals have also allowed an investigation of satellite microphysical retrieval sensitivity to above-cloud water vapor absorption for this region (Painemal and Zuidema, 2011).

For the lower-altitude sub-cloud legs, the water vapor overlying the plane fully saturated the center $183 \mathrm{GHz}$ water vapor absorption line. The emission from the wings of the absorption line retained sensitivity to LWP, however, and LWP can be retrieved given an input water vapor path specified independently using other aircraft datasets. This is a new and different application of the GVR from its previous applications in the Arctic, and the GVR's usefulness for cloud process studies within the dry subtropics are undocumented. This is the purpose of this paper. The exercise will in the future contribute to the performance evaluation of another $183 \mathrm{GHz}$ radiometer simultaneously deployed upon the $R e$ search Vessel Ronald Brown but of different design and calibration technique, the Radiometrics MP-183.
Specifically, we ask:

1. How well do GVR retrievals of free-troposphere WVPs compare to those from radiosondes?

2. Can stratocumulus LWPs be usefully retrieved from just the wing-line emission with other aircraft measurements specifying the boundary-layer WVPs, and if so, to what accuracy?

3. If so, what do the results tell us about the cloud adiabaticity?

The first question anticipates the use of the many radiosondes previously launched in this region. These radiosondes provide the inputs into forward calculations of brightness temperatures that are then used for the WVP retrievals, similar to Racette et al. (2005), Cadeddu et al. (2007), Cimini et al. (2007), and Cimini et al. (2009). The second question explores this study's approach for retrieving LWP, of relying on aircraft state variables and the other cloud remote sensors to specify the boundary-layer WVP. Retrieval accuracy is primarily assessed by taking advantage of the pronounced cloud adiabaticity previously documented for this region (e.g., Bretherton et al., 2004; Zuidema et al., 2005), enough that adiabatic derivations have been used as a LWP proxy for VOCALS-REx (e.g., Bretherton et al., 2010). The GVR retrievals in turn are used to provide a larger statistical evaluation of cloud adiabaticity, establishing limits on the impact of entrainment and sub-cloud decoupling on cloud processes. This dual function was achieved by first selecting ideal adiabatic conditions for the retrieval assessment, and then evaluating adiabaticity statistics from a full dataset of approximately $600001 \mathrm{~Hz}$ samples, equivalent to $\sim 6000 \mathrm{~km}$ of distance sampled at an aircraft flight speed of $100 \mathrm{~m} \mathrm{~s}^{-1}$.

\section{Background: initial retrieval design, further instrument description, and radiative absorption models}

\subsection{Initial retrieval considerations}

Approaches for deriving LWPs from the GVR measurements include a neural net algorithm (Pazmany, 2007) and a fourchannel physical retrieval (Cadeddu et al., 2007). These algorithms were developed from mid-latitude winter and Arctic temperature and moisture profiles that are not representative of subtropical stratocumulus conditions. In particular, the center absorption lines did not saturate. We developed initial expectations from forward radiative transfer calculations of brightness temperature based on radiosonde moisture and temperature profiles from seven buoy-tending cruises occurring between the years 2001 through 2008. These sampled the full diurnal cycle at regular intervals, and spent 6-7 days at $85^{\circ} \mathrm{W}, 20^{\circ} \mathrm{S}$, and $\sim 3$ days along $20^{\circ} \mathrm{S}$ to the coast 

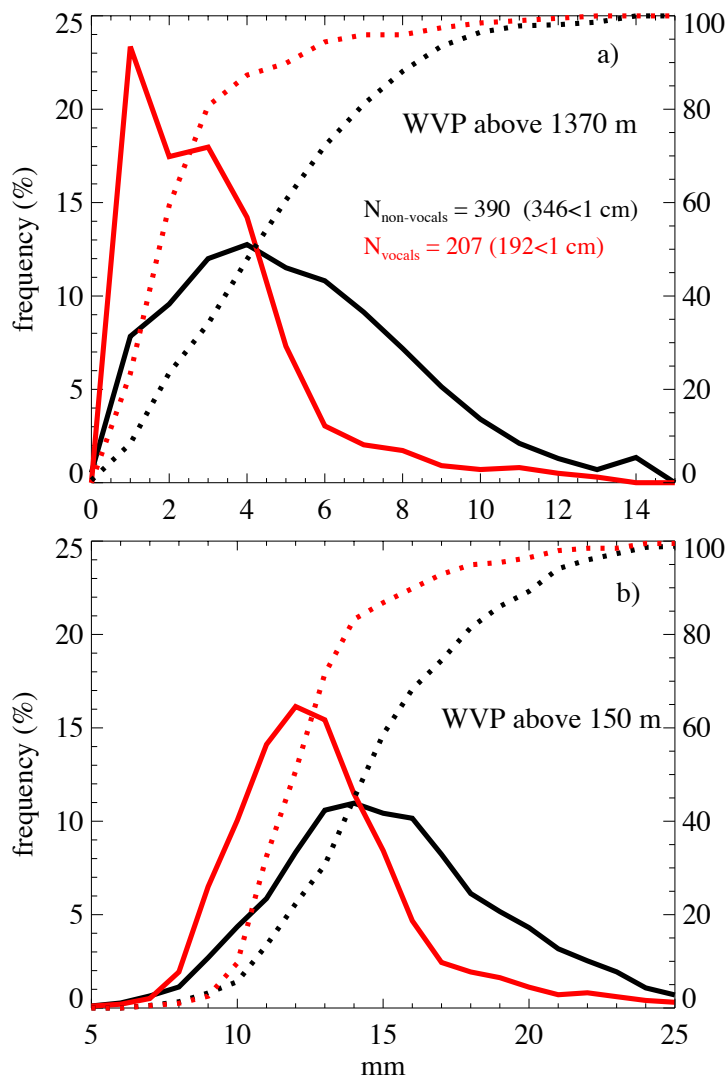

Fig. 1. (a) Histogram of free-tropospheric water vapor path values calculated from ship-board radiosondes prior to VOCALS-REx, and VOCALS-REx separately (black and red lines, respectively). Dotted lines indicate the cumulative frequency of occurrence. (b) Same as (a) but for the water vapor paths overlying the sub-cloud aircraft legs at $150 \mathrm{~m}$ altitude. All radiosondes were released between $0^{\circ}$ and $23^{\circ} \mathrm{S}$ and east of $97^{\circ} \mathrm{W}$ and all reached at least $200 \mathrm{hPa}$.

(or vice versa). All but two of the cruises took place in October and all the post-2001 cruises used the more accurate Vaisala RS-90 series radiosondes. The cruises are described more fully in Zuidema et al. (2009), de Szoeke et al. (2010), de Szoeke et al. (2011) and references therein. Histograms of the water vapor paths for the years prior to VOCALS-REx and separately for the VOCALS cruise are shown in Fig. 1. Free-tropospheric WVPs (calculated from $1370 \mathrm{~m}$ altitude, the mean above-cloud aircraft height) during VOCALS-REx were low compared to other years, typically $<0.5 \mathrm{~mm}$ with outliers up to three $\mathrm{mm}$. Radiosonde-derived water vapor paths calculated at $150 \mathrm{~m}$, a representative altitude for the aircraft sub-cloud legs, also show VOCALS-REx WVPs lower than for other years, with values between eight to twenty $\mathrm{mm}$ (Fig. 1b).

Several choices were made within the forward radiative transfer calculations based on the soundings. Brightness temperatures $\left(T_{b}\right)$ calculations for the center lines can be sensitive to stratospheric water vapor (providing the basis for satellite remote sensing of moisture). The sensitivity is most pronounced for WVPs $<1 \mathrm{~mm}$ and thus could potentially influence the free-tropospheric WVP retrievals. Racette et al. (2005) and Cadeddu et al. (2007) concluded that uncertainty in the specification of water vapor above $10 \mathrm{~km}$ could only explain a difference of $\sim 1 \mathrm{~K}$ in the center line $T_{b}$, however, later supported by Payne et al. (2008). Thus, a climatological stratospheric sounding extrapolated onto the radiosonde soundings reaching at least $50 \mathrm{hPa}$ altitude was deemed sufficient, as also done within Cadeddu et al. (2007) and Payne et al. (2008). In addition, although in theory the $T_{b}$ s could be increased by scattering from high-altitude ice crystals, the observed cirrus fraction was low and clouds thin, with previous studies reporting negligible scattering for ice particle sizes $<200 \mu \mathrm{m}$ (e.g., Buehler et al., 2007; Cimini et al., 2007). We did not consider cirrus scattering. Vaisala RS-90 soundings do contain a small daytime solar heating bias, estimated at $5 \%$ (Miloshevich et al., 2009), but otherwise brightness temperatures calculated from Vaisala RS-90 series radiosondes have compared well to GVR measurements in the Arctic (Payne et al., 2008) and to chilled mirror hygrometers (Miloshevich et al., 2006) using the above assumptions.

The downwelling $T_{b}$ s corresponding to the 10th and 90th percentile of 300 Vaisala RS-92 radiosondes reaching $50 \mathrm{hPa}$ are shown for the $0-220 \mathrm{GHz}$ frequency range in Fig. 2, bottom panel, (black and red solid lines respectively), and for the $165-200 \mathrm{GHz}$ range (top panel). The spectra corresponding to the above-cloud legs (purple and yellow lines) show the center lines retaining their sensitivity to moisture. At $150 \mathrm{~m}$ altitude the center absorption lines are fully saturated, while the wing lines retain a strong sensitivity to LWP regardless of WVP.

The sensitivity of the two outer wing line $T_{b}$ s to liquid water path is shown in more detail in Fig. 3. The $\pm 7 \mathrm{GHz} T_{b} \mathrm{~s}$ (red lines) are less sensitive to LWP changes in more moist conditions, while the outer wing lines $( \pm 14 \mathrm{GHz}$, black lines) remain responsive to liquid water changes $-\frac{\delta T_{b}}{\delta L W P}$ sensitivities between $0.6-1.5 \mathrm{~K}_{\text {per }} 10 \mathrm{~g} \mathrm{~m}^{-2}$ depending on water vapor. Initial assessments suggested the \pm 7 and $14 \mathrm{GHz}$ channels performed equally well. For the work presented here, the choice was made early on to base the LWP retrieval on just the $\pm 14 \mathrm{GHz} T_{b}$ because that radiance was more highly sensitive, and more linearly sensitive, to liquid water path than the $\pm 7 \mathrm{GHz} T_{b}$. Nevertheless, the combination of the \pm 7 and $\pm 14 \mathrm{GHz} T_{b}$ s could potentially reduce the sensitivity of the retrieval to uncertainties in the inputs, particularly the boundary layer WVP. Its assessment remains outside of the scope of the work presented here, but is a worthwhile future activity.

\subsection{G-band vapor radiometer instrument design and calibration}

The GVR measures brightness temperatures from four double-sideband channels, centered at $\pm 1, \pm 3, \pm 7$, and 


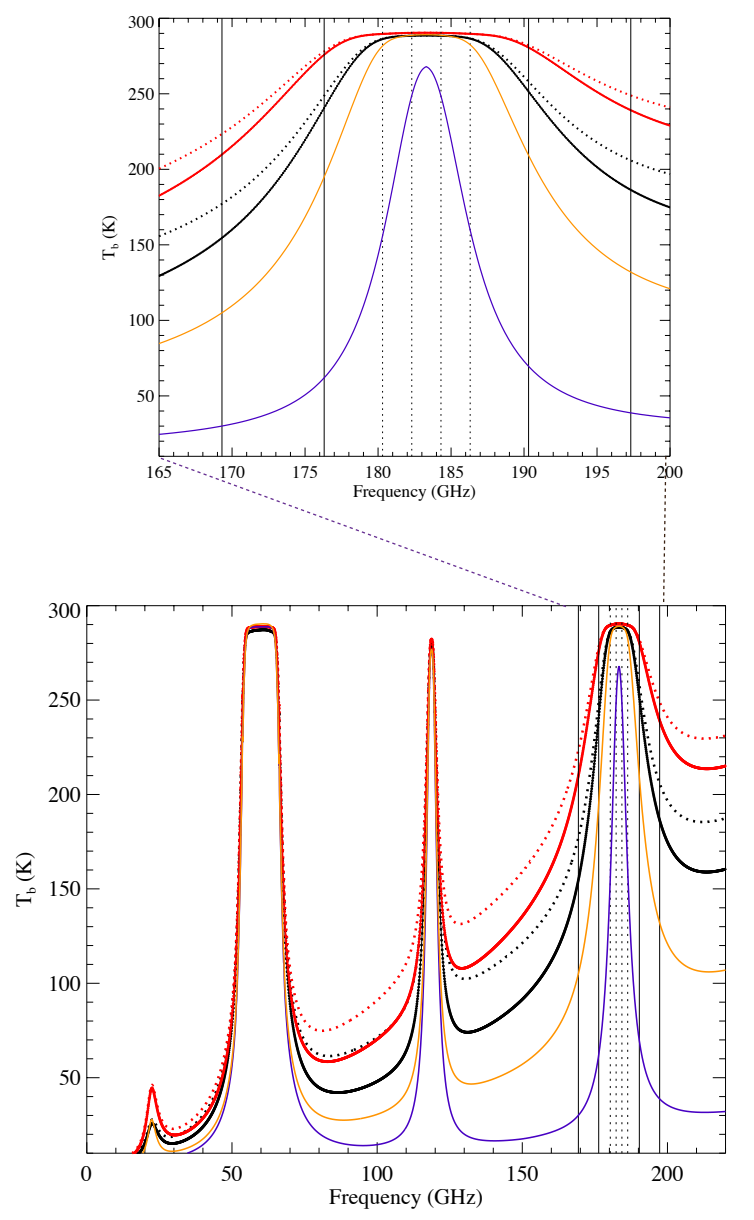

Fig. 2. Downwelling brightness temperatures at $150 \mathrm{~m}$ altitude calculated using the 10th and 90th percentile of the 330 RS-92 radiosondes reaching $50 \mathrm{hPa}$ (WVPs of 11 and $21 \mathrm{~mm}$, black and red lines respectively), for $0-220 \mathrm{GHz}$ (bottom panel) and 165$200 \mathrm{GHz}$ (top panel). Cloudy-sky (LWP $=100 \mathrm{~g} \mathrm{~m}^{-2}$, cloud base at $1 \mathrm{~km}$ ) spectra are shown as dashed lines. Above-cloud spectra at $1370 \mathrm{~m}$ are also shown (WVPs of 1.9 and $9.8 \mathrm{~mm}$, purple and yellow lines, respectively). Thin vertical lines indicate GVR frequencies, these are combined into four double-sideband values within the radiometer.

$\pm 14 \mathrm{GHz}$ off of the $183.31 \mathrm{GHz}$ water vapor absorption line (Pazmany, 2007). The absorption spectrum for LWP is not symmetric around $183 \mathrm{GHz}$ (evident in Fig. 3). The instrument bandwidths are $0.5,1.0,1.4$ and $2.0 \mathrm{GHz}$ for the $\pm(1$, 3,7 , and 14) GHz center frequencies, whereas the $T_{b}$ calculations were monochromatic and centered within the bandwidth. In addition, we assumed that each of the two sidebands contributed evenly to the measurement. All of these assumptions may affect the comparison of the GVR measurements to the radiosonde-calculated $T_{b} \mathrm{~s}$, but they seem reasonable given the passband frequency response shown in Fig. 2 of Pazmany (2007).

Salient details relevant for understanding the instrument calibration, provided within Pazmany (2007) and Cadeddu

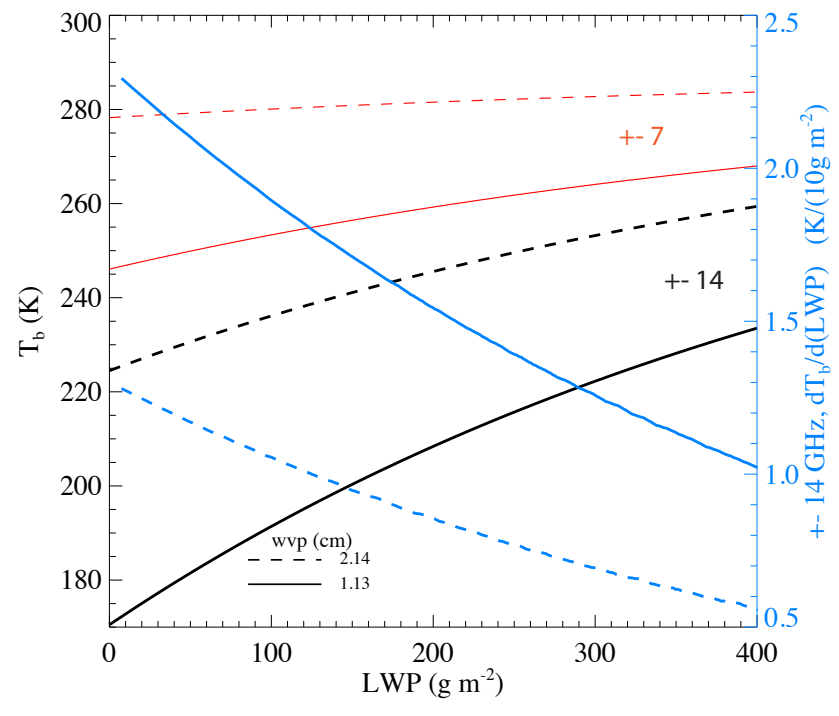

Fig. 3. Brightness temperatures for the outer wing channels $( \pm 14$ and $\pm 7 \mathrm{GHz}$; black and red lines respectively) as a function of liquid water path at $150 \mathrm{~m}$ altitude for the 10th and 90th percentile (dashed and solid lines) water vapor profiles represented in Fig. 2. $T_{b}$ sensitivity to LWP for the $\pm 14 \mathrm{GHz}$ channel is shown in blue, with values indicated on right-hand axis.

et al. (2007), are repeated here. The sky brightness temperatures are calculated internally using receiver gain and offsets determined from two reference loads at set temperatures (Pazmany, 2007); these were about $295 \mathrm{~K}$ and $333 \mathrm{~K}$ during VOCALS-REx. The receiver gain and offset were monitored through viewing the two loads approximately once every ten seconds on a continuous cycle. This frequent monitoring reduced the impact of receiver temperature fluctuations upon the calculated sky brightness temperatures. The absolute accuracy of the reported load temperatures is approximately $0.2 \mathrm{~K}$ (Pazmany, 2007), which could in theory correspond to an error in the sky brightness temperature of almost $3 \mathrm{~K}$ (Cadeddu et al., 2007). This is considered to be the most significant source of calibration error (Cadeddu et al., 2007). An estimate of the absolute calibration was done in Barrow, Alaska by comparing the ground GVR measurements to radiosondes and other millimeter-wave radiometers and arrived at $\sim 2 \mathrm{~K}$ (Cadeddu et al., 2007; Cimini et al., 2009). An independent external assessment of the airborne GVR, done immediately prior to VOCALS-REx, found all four $T_{b}$ measurements within $1 \mathrm{~K}$ of each other and of the calibration target. We assume a $2 \mathrm{~K}$ calibration error estimate here to be consistent with the stated accuracy of the internal temperature sensors (Pazmany, 2007).

The channel noise provides an estimate of the relative calibration (i.e., the accuracy of individual values compared to their neighbors). It depends on the integration time, bandwidth, and, receiver noise temperature, and is estimated at $0.2 \mathrm{~K}$ at a $200 \mathrm{~ms}$ integration time (Pazmany, 2007). It can 


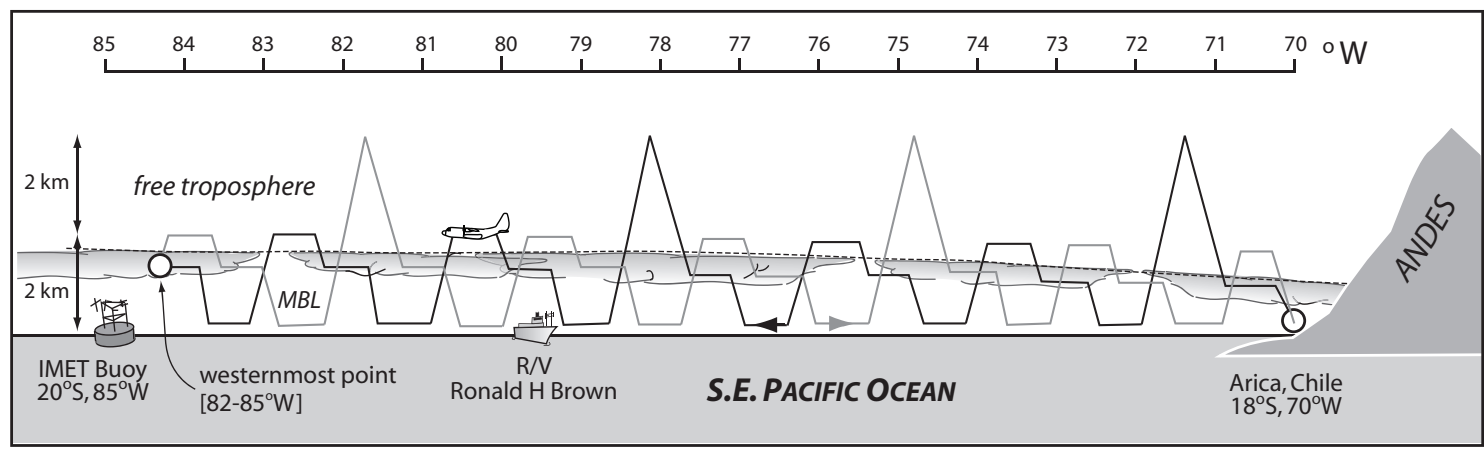

Fig. 4. The NCAR C-130 flight plan along $20^{\circ} \mathrm{S}$, with the outward leg in black and return leg in grey. Figure provided by Robert Wood, see Wood et al. (2011b) for more information on flight plans and aircraft instrumentation.

be assessed experimentally using a time series within highly homogeneous conditions. We evaluated several random 21$\mathrm{s}$ time series from the outgoing ferry leg of flight RF9 at $5.3 \mathrm{~km}$, and found representative standard deviations of $(0.8$, $0.3,0.3$, and 0.4$) \mathrm{K}$ for the $\pm(1,3,7$, and 14) $\mathrm{GHz}$ lines. These support the published estimate and we chose $0.3 \mathrm{~K}$ as a representative value.

A temporal resolution of $1 \mathrm{~s}$ was desired for the reported brightness temperatures, to be on a common framework with that of other remote sensing measurements. This corresponds to an approximate $1 \mathrm{~Hz}$ measurement rate with occasional $0.25 \mathrm{~s}$ calibration gaps. The retrieved LWPs represent the average over a horizontal aircraft transect leg of $\sim 30 \mathrm{~m}$, estimated from the antenna beamwidth of $1.7^{\circ}$ and an aircraftdistance-to-cloud of $500 \mathrm{~m}$.

\subsection{C-130 Flight details, Wyoming cloud radar, Wyoming cloud lidar, and ancillary datasets}

Fourteen C-130 research flights sampled the SEP atmosphere in October and November of 2008, eight at night and six during the day. Four of the nighttime flights sampled along $20^{\circ} \mathrm{S}$ out to $85^{\circ} \mathrm{W}$. Its flight plan, shown in Fig. 4, was typical of all missions in that it dedicated ten minutes each to sub-cloud legs (SC; $\sim 150 \mathrm{~m}$ altitude), cloud-base legs, and above-cloud legs (AC). The above-cloud legs occurred at $\sim 200 \mathrm{~m}$ above the cloud top for a mean above-cloud flight altitude of $1370 \mathrm{~m}$, with cloud top heights varying between one to two km (Bretherton et al., 2010; Rahn and Garreaud, 2010). Other flights sampled open cellular convection with legs of 40 min duration. Several of the daytime flights sampled along the coast. More details on overall aircraft performance and individual flights are available within Wood et al. (2011b).

The WCR and WCL provided the cloud boundaries needed for the adiabatic LWP calculation. The radar was situated towards the rear of the plane and the lidar and GVR were located more centrally. For this study only the upwardpointing beam of the $94 \mathrm{GHz}$ radar was used. The cloud radar detected cloud top given sufficiently strong scatterers, at a vertical resolution of $30 \mathrm{~m}$. The cloud lidar possessed a vertical resolution of $3.75 \mathrm{~m}$, and provided a sensitive detection of cloud base even in the presence of precipitation (if more variable). At times, the presence of scud - a lower, secondary cloud layer formed from precipitation-moistened air - inflated the cloud thickness estimate attributed to the active overlying single-layer cloud (e.g., Fig. 14 of Bretherton et al., 2010). During the RF9 flight, the lidar laptop did not record data and that flight is excluded from all the statistics presented here. Prior to RF9, the lidar computer clock occasionally drifted. This was corrected for as best possible by removing time discontinuities between the GVR and adiabatic LWP time series when they were expected to match. Excluding the RF9 flight, $605901 \mathrm{~Hz}$ samples were collected.

The cloud base height $\left(Z_{c b}\right)$ combined with the lifting condensation level was used as a measure of boundary layer mixing. ( $Z_{c b}$-LCL) differences greater than $125 \mathrm{~m}$ were taken to indicate decoupled boundary layers, following Jones et al. (2011), who found the difference corresponded to an approximate $0.5 \mathrm{~g} \mathrm{~kg}^{-1}$ difference in the total mixing ratio between the bottom $25 \%$ and upper $25 \%$ of the boundary layer. Initial calculations found LCLs that exceeded $Z_{c b} \mathrm{~s}$, and an offset of $0.8 \mathrm{~K}$ was added to the reported dewpoint temperatures to bring the LCL and $Z_{c b}$ into agreement for non-precipitating well-mixed conditions (Bretherton et al., 2010). This also allowed in-cloud relative humidity readings to reach $100 \%$. Last, the cloud base temperature $\left(T_{c b}\right)$ was used within the boundary layer WVP specification. $T_{c b}$ was determined from a Heimann radiometric sensor measuring radiation between 9.5 to $11.5 \mu \mathrm{m}$ with a stated accuracy of $\pm 0.5 \mathrm{~K}$.

Adiabatic calculations were only done when both radar and lidar identified their respective cloud boundaries, primarily selecting for thicker clouds. These comprised $40 \%$ of the total samples, and the comparison of retrieved to adiabatic LWPs was restricted to these. For thin clouds the lidar could detect a cloud base but a radar-based algorithm might not identify a cloud top. For such cases, the altitude of the 
Table 1. Number of $1 \mathrm{~Hz}$ samples influencing cloud boundary statistics from thirteen research flights (these excluded RF9). Radar returns include those for which the altitude of maximum reflectivity is used as a cloud top proxy. Cloud-base legs are excluded. The percentages assume a total of 60590 .

\begin{tabular}{llccc}
\hline & $\begin{array}{l}\text { lidar returns } \\
\text { (cloud base) }\end{array}$ & $\begin{array}{c}\text { radar returns } \\
\text { (cloud top) }\end{array}$ & $\begin{array}{c}\text { adiabatic } \\
\text { LWPs }\end{array}$ & $\begin{array}{c}\text { clear-sky } \\
\text { (no lidar/radar) }\end{array}$ \\
\hline$N$ & 51836 & 41449 & 24192 & 4918 \\
$\%$ & 85.5 & 68.4 & 40.0 & 8.1 \\
\hline
\end{tabular}

radar return with the maximum reflectivity, if available, was used to establish the cloud top for the GVR LWP retrieval. Only time series containing a consistent lack of returns were deemed clear-sky. Statistics on the cloud boundaries for the sub-cloud legs only are summarized in Table 1.

\subsection{Millimeter-wavelength absorption models}

The correspondence between sonde-calculated $T_{b}$ s and the GVR measurements also depended on the microwave absorption models used to convert radiosonde moisture and temperature profiles into microwave brightness temperature values. Previous work at 22 and $30 \mathrm{GHz}$ frequencies favored the Liljegren et al. (2005) gaseous absorption model, itself modified from Rosenkranz (1998) for this stratocumulus region (Zuidema et al., 2005). For the current work we further modified the Liljegren et al. (2005) gaseous absorption model to include the water vapor continuum coefficients in Table IV of Turner et al. (2009). This was done to address concerns that LWPs retrieved using all four $183 \mathrm{GHz}$ channels could be markedly smaller than those using the 22$30 \mathrm{GHz}$ channels (Cadeddu et al., 2007), perhaps because of the spectroscopic specification of the $183 \mathrm{GHz}$ absorption line (Payne et al., 2008) and/or the water vapor continuum line (Hewison, 2006). Our modification of the water vapor continuum coefficients brings intermodel differences to within $2 \mathrm{~K}$ over the window regions between 10 to $400 \mathrm{GHz}$ Turner et al. (2009). The modification primarily impacts the \pm (14 and 7) $\mathrm{GHz}$ channels.

The GVR liquid water path calculations also relied on the Liebe et al. (1991) and Liebe et al. (1993) liquid dielectric models. Water permittivity models are more difficult to evaluate than gaseous absorption models, but the Liebe et al. (1993) model has produced results similar to that of other models in the $10^{\circ}-20^{\circ} \mathrm{C}$ range (Cadeddu and Turner, 2011). The more important limitation to our radiative transfer calculations is an assumption of Rayleigh scattering and attenuation: at the radiometer wavelength of $\sim 1.66 \mathrm{~mm}$, Mie scattering and attenuation effects can be locally large within heavy stratocumulus precipitation. The scattering and attentuation effects do partially compensate for each other. We did not explore this further here, but this needs to be researched more thoroughly.
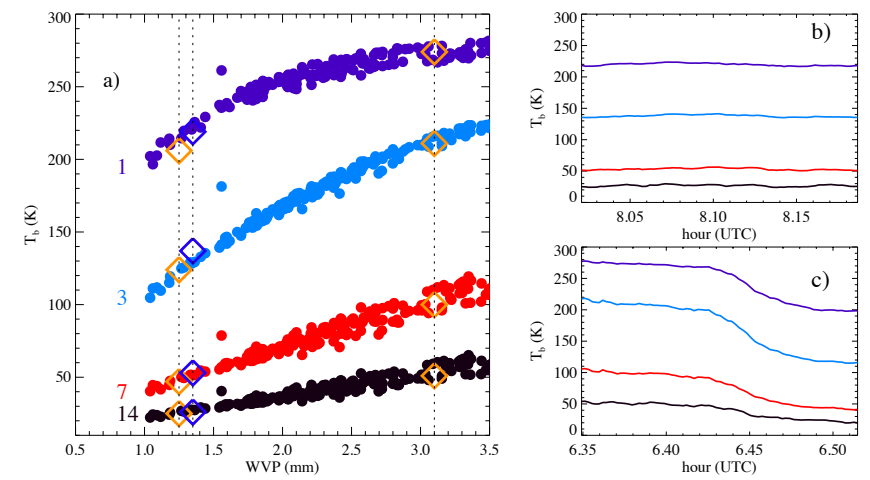

Fig. 5. (a) Simulated $T_{b}$ for the $\pm 1, \pm 3, \pm 7$, and $\pm 14 \mathrm{GHz}$ GVR channels calculated for $330 \mathrm{RS} 92$ soundings reaching $50 \mathrm{hPa}$ (purple, blue, red, and black filled circles, respectively) at the RF3AC1 altitude of $1335 \mathrm{~m}$, and GVR leg-mean values for RF3AC3 (blue diamonds, collected at $1548 \mathrm{~m}$ altitude and shown only for comparison) and 5-min mean values for RF3AC1 (yellow diamonds). Time series of GVR $T_{b}$ s for (b) RF3AC3 and (c) RF3AC1, with $\pm(1,3$, 7 , and 14$) \mathrm{GHz}$ lines indicated in purple, blue, red, and black respectively.

\section{Free troposphere water vapor path retrieval calculations and assessment}

Measurements and calculations done for the above-cloud $\mathrm{RF} 3 \mathrm{AC} 1$ leg are used to demonstrate the retrieval of the free troposphere WVP. Brightness temperatures calculated from 330 VOCALS-REx RS-92 radiosondes at $1335 \mathrm{~m}$, the RF3AC1 aircraft altitude, are shown as a function of WVP in Fig. 5a. The $T_{b}$ response to increasing WVP is mostly linear for the wing lines, while the center line shows a non-linear response as WVPs increase beyond $2 \mathrm{~mm}$. The $\pm 3 \mathrm{GHz} T_{b}$ is the most sensitive of the four lines to WVP variability between 1 to $3.5 \mathrm{~mm}$, maintains the most linear response, and has the least $T_{b}$ variability at a given WVP of the four channels. The spread in the $T_{b}$ values at a given WVP indicates sensitivity to the water vapor vertical profile and its emission temperature at those heights (Racette et al., 2005). The soundings show that most of the meteorological $T_{b}$ variability originated from free-tropospheric moisture variability at $\sim 5 \mathrm{~km}$ and in the upper troposphere (Fig. 6).

The off-shore free-tropospheric brightness temperatures did not typically vary much over the $\sim 72 \mathrm{~km}$ distance of one leg (e.g., Fig. 5b). This is expected for a strongly-subsiding atmosphere with little variation in the free-tropospheric WVPs. The average of nine RF3 above-cloud leg-mean $T_{b}$ standard deviations (between-leg variation was little and AC1 was excluded) was $(3.2,3.0,1.8,1.6) \mathrm{K}$ for the $\pm(1$, 3,7 , and 14) GHz channels. The center line was the most variable as it was the most sensitive to low clear-sky WVP values. Near the coast, continental moisture outflow can give rise to gradients in the measured $T_{b} \mathrm{~s}$. The gradients were typically local, within $\sim 10 \mathrm{~km}$ (e.g., Fig. 5 c). We typically 


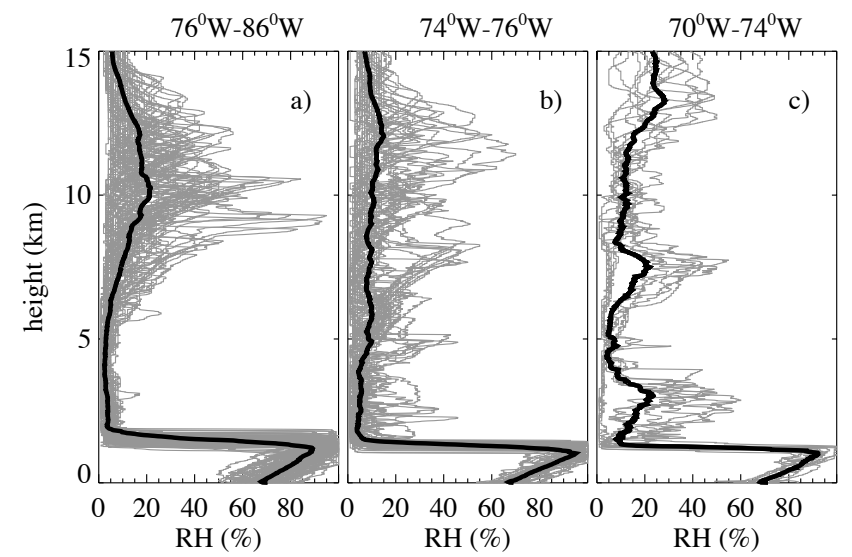

Fig. 6. Ship-launched soundings during VOCALS-REx along $20^{\circ} \mathrm{S}$ between (a) $76-86^{\circ} \mathrm{W}(N=77)$, (b) $74-76^{\circ} \mathrm{W}(N=50)$, and (c) $70-74^{\circ} \mathrm{W}(N=11)$. Black lines indicate mean soundings for each longitude bin.

estimated a leg-mean WVP value from a best-fit of the four GVR $T_{b}$ s to the forward-calculated radiosonde-derived $T_{b} \mathrm{~s}$ done at leg-mean aircraft altitude. Near the coast the leg measurements were split into two halves. Example WVP values are shown in Fig. 5a for the two legs shown in Fig. 5b and c. If an initial WVP estimate is made using a best-fit to the $\pm 3 \mathrm{GHz}$ line only, the deviations from the other channels suggest a conservative WVP error estimate of $\sim 0.2 \mathrm{~mm}$.

\subsection{Comparison to R/V Ron Brown sonde}

The above-cloud GVR $T_{b}$ s were independently assessed by comparing GVR values from three C-130 overflights of the R/V Ronald Brown to $T_{b}$ s calculated from ship soundings. The three overflights occurred on 25 October (RF5), 2 November (RF8), and 11 November (RF12). The comparisons are shown in Fig. 7. The nighttime 2 November comparison was the most robust (Fig. 7a), in that it was free of a known dry daytime humidity bias (Miloshevich et al., 2009), and a sounding was launched near in time to the overflight. The two aircraft above-cloud legs occurred $18 \mathrm{~min}$ prior and $41 \mathrm{~min}$ to a sounding, approximately $100 \mathrm{~km}$ east and $50 \mathrm{~km}$ west of the ship. The GVR $T_{b}$ s exceeded the radiosondederived values, most notable for the center lines. The 11 November afternoon GVR $T_{b}$ s also exceeded the radiosondecalculated values, even after allowing for a $5 \%$ difference due to radiosonde solar absorption (Fig. 7b). The closest 25 October aircraft-ship match is also shown for completeness (Fig. 7c) but adds little information (GVR data were lacking from the direct overpass of the R/V Ron Brown).

The comparisons of the measurements to the radiosondecalculated values (Fig. 7) suggest the GVR $T_{b}$ s may be biased high. For 2 November, GVR-estimated WVPs of $2.0 \mathrm{~mm}$ and $1.5 \mathrm{~mm}$ (at 1.38 and $1.60 \mathrm{~km}$ altitude) exceeded the radiosonde-derived values of 1.42 and $1.27 \mathrm{~mm}$ by 0.6 and
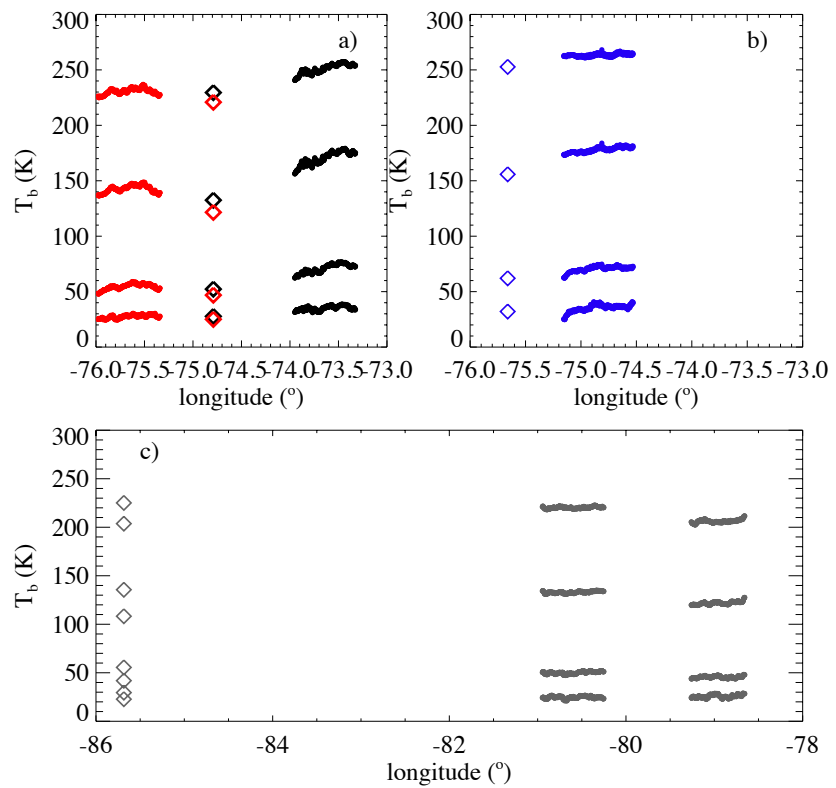

Fig. 7. (a) Two 2 November above-cloud overpasses, RF8 AC2 and AC4, occurring at 07:04:20 and 08:03:20 UTC, and 1.38 and $1.6 \mathrm{~km}$ altitude, shown using black and red time series traces respectively for all four channels, with the warmest values corresponding to the $\pm 1 \mathrm{GHz}$ channel. The $T_{b} \mathrm{~s}$ simulated from a ship-launched radiosonde at 07:22:20 UTC at 1380 and $1600 \mathrm{~m}$ altitude are shown as black and red diamonds respectively. (b) measured $T_{b} \mathrm{~s}$ during a 11 November, 19:59:40 overpass (RF12) at $1410 \mathrm{~m}$ altitude and calculated $T_{b}$ s from a radiosonde launched at 20:50:00 UTC (diamonds). (c) measured $T_{b}$ s from above-cloud legs on 25 October (RF5) at 09:22:00 and 12:47:00, and $T_{b}$ s calculated from radiosondes launched at 07:23:00 and 11:16:00 UTC (diamonds).

$0.2 \mathrm{~mm}$ respectively (Fig. 7a). The longitudinal $T_{b}$ gradient of the eastern flight leg, if extrapolated, may explain some of the $0.6 \mathrm{~mm}$ discrepancy. The comparison at $\pm 3 \mathrm{GHz}$ was the worst of the four channels, however, and can also be seen on Fig. 5. This line is nearest to the spectroscopic 'pivot point', at which specifications in line width and intensity should compensate for each other (Payne et al., 2008). Nevertheless, both Payne et al. (2008) and Turner et al. (2009) indicate that the spectroscopy of the center $183.31 \mathrm{GHz}$ absorption line may require further refining, which is at least consistent with the offset shown here. We lacked the means for further evaluation. Almost all cases showed a good general correspondence, similar to that in Fig. 5. For above-cloud leg segments with little $T_{b}$ variability, we estimate the error in the retrieved WVP at $0.2 \mathrm{~mm}$. The along-coast flights experienced the most $T_{b}$ variability and may have larger errors in their retrieved WVPs. 
Table 2. Major error sources within the GVR LWP retrieval

\begin{tabular}{l|ll}
\hline error source & $\delta T_{b}(\mathrm{~K})$ & $\delta \mathrm{LWP}\left(\mathrm{g} \mathrm{m}^{-2}\right)$ \\
\hline$\delta\left(\mathrm{WVP}_{\text {freetroposphere }}\right)$ of $0.2 \mathrm{~mm}$ & 1 & $6-10$ \\
relative calibration & 0.3 & $2-3$ \\
absolute calibration & 2 & $10-20$ \\
absorption model & 2 & $10-20$ \\
$\delta\left(\mathrm{WVP}_{\text {boundarylayer }}\right)$ of $0.2 \mathrm{~mm}$ & 1 & $6-10$ \\
\hline
\end{tabular}

\section{Cloud liquid water path retrieval}

The free-tropospheric WVPs retrieved from the above-cloud legs were summed with boundary-layer WVPs computed from in-situ thermodynamic data, and the total WVP used as an input into the LWP retrieval. The boundary layer water vapor path was calculated, at $1 \mathrm{~Hz}$ resolution, by integrating the in-situ water vapor mixing ratio from flight level up to the lifting condensation level. If the LCL was higher than half-way from the flight level to cloud base, the in-situ water vapor mixing ratio was integrated up to one-half the distance from the flight level to $Z_{c b}$, and the cloud base mixing ratio used thereafter. This was done to account for decoupled conditions, for which the water vapor mixing ratio at cloud base might not match the in-situ vapor mixing ratio. The cloud base temperature $\left(T_{c b}\right)$ was estimated from the larger of the $T_{c b}$ estimated by the aircraft infrared radiometer, or, that estimated using a dry adiabatic lapse rate. Above cloud base, liquid water was adiabatically removed from the water vapor mixing ratio up to the radar-inferred cloud top.

Several limitations exist to this methodology. The radiometrically inferred $T_{c b}$ can be underestimated if the cloud is in fact a greybody, i.e., when LWPs $<30 \mathrm{~g} \mathrm{~m}^{-2}$. The inferred $T_{c b}$ can also be overestimated because of unaccounted-for water vapor emission. In highly-decoupled conditions, the use of the dry adiabatic lapse rate may generate an underestimate of the $T_{c b}$. An error in the cloud base temperature or height by $1 \mathrm{~K}$ or $\sim 100 \mathrm{~m}$ is estimated to correspond to an error in the boundary-layer WVP of $0.13 \mathrm{~mm}$, assuming a WVP of $20 \mathrm{~mm}$ distributed over $1.5 \mathrm{~km}$ depth. Similarly, the adiabatic assumption may overestimate the removed liquid water amount. An overestimate of, e.g., $50 \mathrm{~g} \mathrm{~m}^{-2}$ liquid water will only underestimate the boundary layer water vapor path by $0.05 \mathrm{~mm}$. Each of these errors is less than the $0.2 \mathrm{~mm}$ error ascribed to the free-tropospheric WVP. Although all of the limitations mentioned here are unfortunate, none are considered severe. This is ultimately confirmed by the good correspondence between the retrieved and adiabatic LWPs in situations where that is expected. In sum we assign a maximum error of $0.2 \mathrm{~mm}$ to the boundary layer WVP specification, with smaller values expected for well-mixed boundary layers.

The LWP retrieval itself was modified from that of Zuidema et al. (2005). An estimate of the cloud tempera- ture (to which the millimeter-wave absorption is sensitive) was made from the cloud boundaries combined with temperature sounding composites done at three off-shore distances: coastal, $300-600 \mathrm{~km}$, and $600-1000 \mathrm{~km}$, similar to Fig. 6 but done for temperature. Errors of a couple of degrees in inferred cloud temperature only have a small impact on the millimeter-wave emission, and cloud boundaries were defined more leniently within the retrieved LWP calculation than for the adiabatic calculation. If local cloud boundary information was missing, either the neighboring or the legmean cloud boundaries were used. If no radar cloud top was determined during the entire leg (more likely to occur than no cloud bases), a cloud top height was estimated from the neighboring ascent and/or descent legs. For the RF9 flight (9 November), the cloud bases were solely estimated from the aircraft profile legs, and although GVR LWP retrievals were done, their accuracy is unknown. The retrieval then consisted of forward-computing brightness temperatures as a function of LWP, and iterating on the assumed LWP until a best-fit of the computed $\pm 14 \mathrm{GHz} T_{b}$ to the measured $\pm 14 \mathrm{GHz} T_{b}$ was found. In a couple of near-coastal cases, the LWP iteration could not always be made consistent with the composite temperature profile, adversely affecting the retrieval. Future work could be done to address this; RF13pocs $2 b$ may be one such case.

A summary of the major error sources within the GVR LWP retrieval is given in Table 2. Disregarded errors include Mie effects, daytime instrumental heating, monochromatic calculations, and the $50 \%$ sideband-weighting. Mie effects on both scattering and emission are considered the most significant of these errors. Errors will be higher within decoupled boundary layers, documented in Sect. 5, and near the coast, where the water vapor path overlying the plane is both higher and more variable. Errors in LWP are estimated from the sensitivities shown on Fig. 3. Figure 3 also shows that errors (sensitivities) decrease with increasing LWP and WVP.

\section{Cloud liquid water path assessment}

Three independent assessments of the GVR LWPs were done. One traditional approach evaluates the non-zero LWP retrievals in conditions deemed clear by the lidar (e.g, Turner et al., 2007). This is less fruitful for the persistently cloudy southeast Pacific conditions (Table 1), but was nevertheless applied to the $8 \%$ of the samples that qualified. We also evaluated the LWPs (or lack thereof) for thin clouds: cases where the lidar detected a cloud base, but the radar did not detect cloud. This occurred in almost $14 \%$ of the total samples and were further broken down by coupled and decoupled sub-cloud conditions $\left(Z_{c b}\right.$-LCL $<$ or $>125 \mathrm{~m}$ respectively). The most statistically-robust approach compared the retrieved LWPs to the adiabatic LWPs (40\% of the total samples). These were also divided further into well-coupled and decoupled cases. 

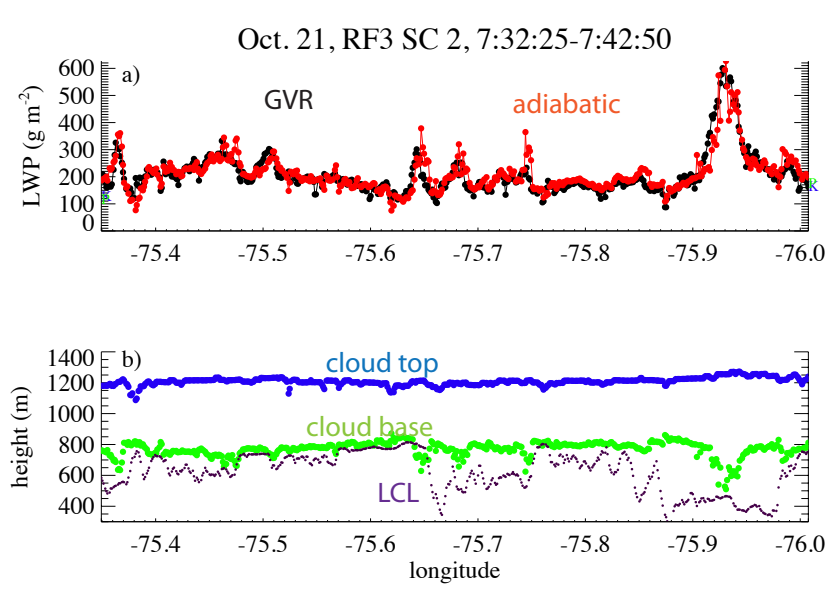

Fig. 8. (a) GVR-retrieved and adiabatically-derived LWP (black and red filled circles respectively) for the RF3 SC2 leg (21 October, 02:32:25-02:42:50 LT). Retrieved and adiabatic LWP means (standard deviations) are 207 (76) and 211 (69) $\mathrm{g} \mathrm{m}^{-2}$ respectively. Pre-descent and post-ascent LWP values derived from the FSSP and King probes are indicated by a small green " $F$ " and blue " $K$ " at beginning and end of the time series. (b) Corresponding lidarinferred cloud base (green), the lifting condensation level (purple), and radar-derived cloud top (blue).

\subsection{Best-case comparison of GVR LWPs to adiabatic LWPs}

Many sub-cloud legs took place in apparently well-mixed boundary layers, but most such layers possessed mean LWPs $\sim 100 \mathrm{~g} \mathrm{~m}^{-2}$ (for a mean cloud thickness $\sim 300 \mathrm{~m}$ ). A cloud thickness uncertainty of $30 \mathrm{~m}$, corresponding to the vertical resolution of the cloud radar, corresponds to a cloud liquid water path uncertainty of $(30 \%, 20 \%, 15 \%)$ for a $(200,300,400) \mathrm{m}$ thick cloud. Thus, thick yet non-drizzling clouds within well-mixed boundary layers are ideal for assessing the GVR LWPs with their adiabatically-derived counterparts.

Our best-case example, from the 21 October RF3 flight, had a mean cloud thickness of $\sim 450 \mathrm{~m}$ and a mean LWP slightly above $200 \mathrm{~g} \mathrm{~m}^{-2}$ (RF3SC2, Fig. 8), with the cloud base and LCL often closely aligned. The above-cloud WVP was 1.2 and $1.5 \mathrm{~mm}$ before and after this leg; values were linearly interpolated across the sub-cloud leg. The columnmaximum radar reflectivity fluctuated between -20 and -10 $\mathrm{dBZ}$ and a robust radar-inferred cloud top was observed continually. The bordering aircraft ascents and descents indicated well-mixed conditions with minimal cloud-top entrainment. The agreement between the GVR and adiabaticallyderived LWP was excellent, with only a $2 \%$ difference between their means (Fig. 8). This was true even towards the end of the leg, where the boundary layer would be considered decoupled.

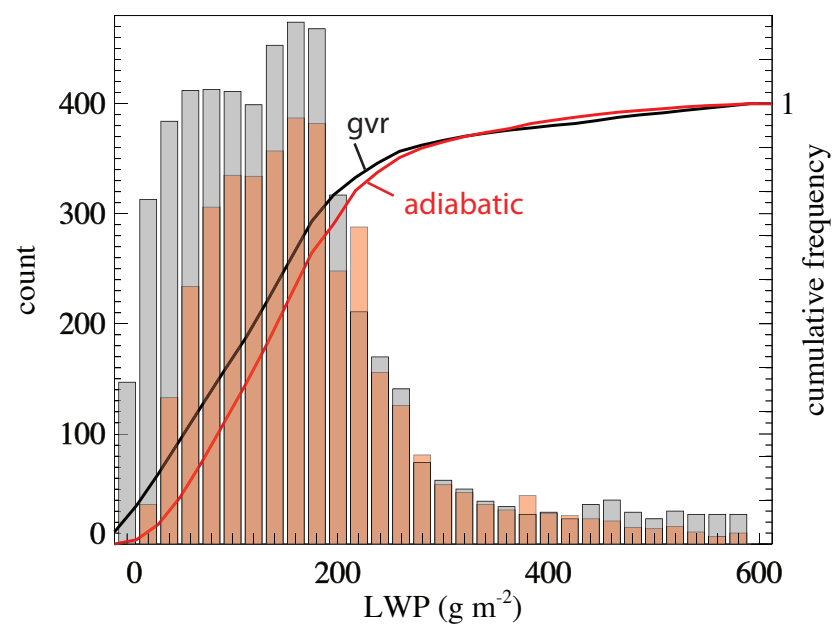

Fig. 9. Distribution of GVR-retrieved (black) and adiabatic (red) LWPs from all nine subcloud legs of the 21 October research flight (RF3). Total number of samples is 5471 and 4003 for the GVR and adiabatic calculation respectively. LWP bins of $20 \mathrm{~g} \mathrm{~m}^{-2}$.

\subsection{Statistical comparison of GVR LWPs to adiabatic LWPs}

In intermittently-coupled legs the correspondence between the adiabatic and GVR LWPs was nevertheless often good (e.g., Fig. 8). The RF3 flight sampled a particularly deep boundary layer with high LWPs and significant precipitation, yet conditions remained overcast, inviting a "best-case" statistical comparison using data from the entire RF3 flight. The GVR and adiabatic LWP distributions from all nine RF3 subcloud legs are shown in Fig. 9. The two distributions were basically identical for LWPs of 200 and $400 \mathrm{~g} \mathrm{~m}^{-2}$, lending further confidence to the GVR retrievals. The GVR LWPs exceeded the adiabatic LWPs for LWPs $>400 \mathrm{~g} \mathrm{~m}^{-2}$. One plausible explanation is that Mie scattering from the larger drop sizes encouraged an overestimate of the actual LWP. For LWPs $<200 \mathrm{~g} \mathrm{~m}^{-2}$, the most likely explanation for the greater frequency of GVR-retrieved LWPs is the generally lower radar reflectivities of the thinner clouds, so that a cloud top height was less likely to be reported and an adiabatic calculation not done.

\subsection{LWPs in clear-sky conditions}

Skies considered clear by the lidar were likely to also be considered clear by the GVR. LWPs retrieved within the clear-sky conditions of the subcloud legs for thirteen research flights totaled 4918 samples, or $8.1 \%$ of the total (Table 1). Their distribution is shown in Fig. 10a. Clear skies, within this data sample, possessed a LWP cloud fraction of $3 \%$, and $80 \%$ of the retrieved LWPs were $<20 \mathrm{~g} \mathrm{~m}^{-2}$. 


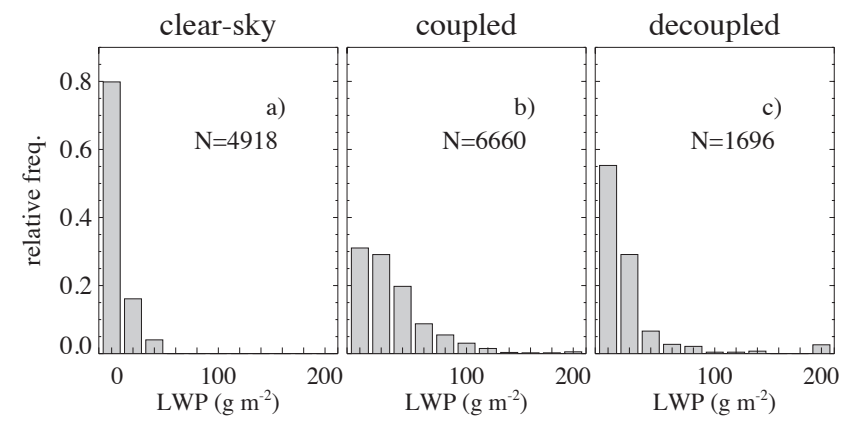

Fig. 10. Frequency distributions of the (a) LWPs in clear-sky conditions (i.e., neither the lidar nor radar provided a valid return), and when only the lidar detected cloud under (b) coupled (CBH-LCL $<125 \mathrm{~m}$ ) and (c) decoupled (CBH-LCL $>125 \mathrm{~m}$ ) conditions. LWP bins of $20 \mathrm{~g} \mathrm{~m}^{-2}$.

\subsection{Cloudy skies without liquid}

Skies for which the lidar sensed a cloud base but the radar did not determine a cloud top should correspond to thin, lowLWP clouds. These totaled $22 \%$ of the 60590 cases. The GVR-retrieved LWPs were also broken down into coupled and decoupled conditions ( $\mathrm{N}=6179$ and 7100 respectively, or $11 \%$ and $12.5 \%$ ). The distributions of the LWPs, when they were retrieved, are shown in Figs. 10b and c. The LWPs retrieved within decoupled conditions were generally lower than in coupled conditions. This is physically plausible because upward moisture transport will be discouraged by the decoupling, but can also be a retrieval artifact. In decoupled conditions the water mixing ratio near cloud base may be reduced from that used to estimate the boundary-layer WVP, and the retrieved LWP will be underestimated - or not retrieved at all. This appears to occur in some cases, as in $74 \%$ of the decoupled conditions, the GVR retrieval was likely to miss the cloud, compared to $59 \%$ of the coupled conditions. Nevertheless, reassuringly, the LWPs, when retrieved, were low, mostly $<40 \mathrm{~g} \mathrm{~m}^{-2}$, in both coupled and decoupled conditions, as expected.

\section{Project-summary results}

\subsection{Free-tropospheric WVPs}

The distribution of the retrieved leg-mean free-tropospheric (above-cloud) water vapor paths are shown as a function of longitude for all fourteen research flights in Fig. 11a, and as a function of latitude for the near-coastal legs (Fig. 11b). Free-tropospheric WVPs were often below $2 \mathrm{~mm}$, and occasionally higher near the coast, particularly above the Arica Bight. Two of the WVP values approaching $10 \mathrm{~mm}$ came from the first and last above-cloud leg for the 23 October (RF4) flight, near Arica. Flight notes reported a haze and pollution layer at $3 \mathrm{~km}$, with the aircraft sounding out of

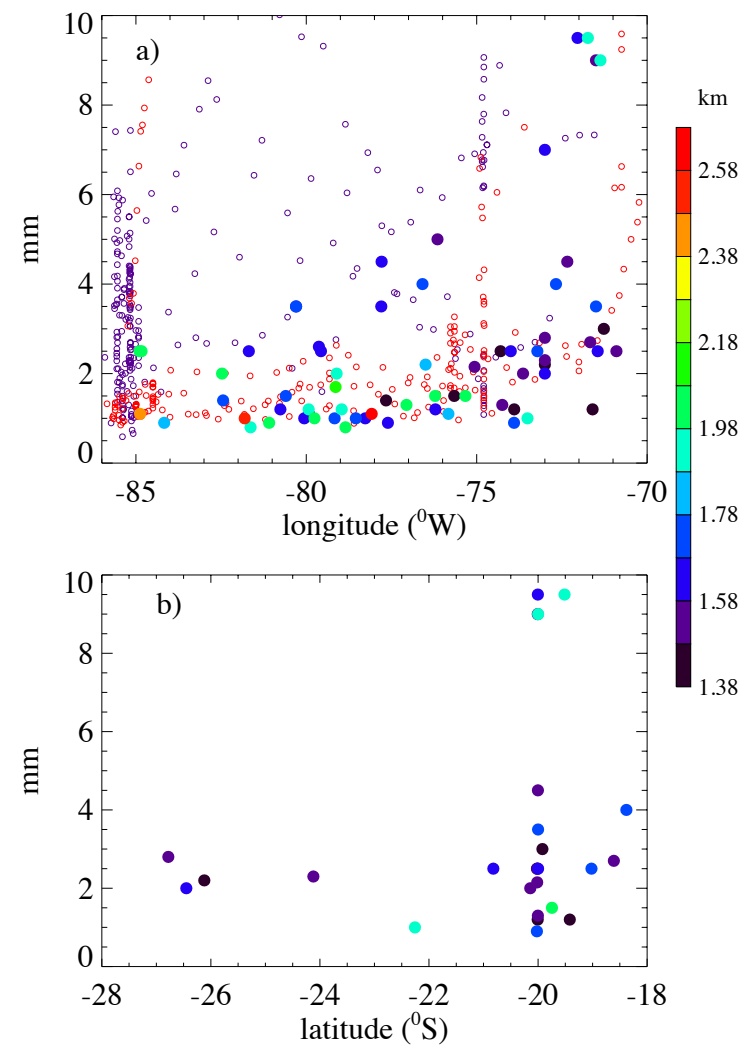

Fig. 11. Free-tropospheric water vapor paths retrieved from the above-cloud legs (a) of all research flights, as a function of longitude (85 legs), and (b) as a function of latitude for longitudes east of $75.5^{\circ} \mathrm{W}$ (42 legs). Colors indicate the leg altitude. Mean flight altitudes, when binned by $2.5^{\circ}$ in longitude from $70^{\circ} \mathrm{W}$ westward, were, in meters, with the number of samples in parentheses: 1495 (14), 1370 (26), 1715 (10), 1695 (19), 1735 (11), and 1855 (5). These altitudes were used to calculate free-tropospheric WVP values from soundings launched from ship during VOCALS (dark orange, $N=207$ ) and cruises during 2001, 2003, 2006 and 2007 (purple, $N=293$ ).

Arica showing relative humidities $>30 \%$ above $3 \mathrm{~km}$. The other high free-tropospheric WVP value of $8 \mathrm{~mm}$ came from 2 November(RF8) from the first above-cloud leg, also near Arica, after the aircraft ascent had sampled a second moisture layer between $2-3 \mathrm{~km}$, with $\mathrm{RH} \sim 30 \%$, above the boundary layer. Most of the higher-WVP points west of $75^{\circ} \mathrm{W}$ came from the daytime flights.

Sounding-derived water vapor paths are also shown in Fig. 11 for VOCALS-REx (orange, 207 sondes) and the October-November cruises in 2001, 2003, 2006 and 2007 (purple, 293 sondes), calculated using the mean above-cloud aircraft altitude for each $2.5^{\circ}$ bin. These show that the GVRand sonde-derived values for 2008 were similar, despite different sampling days, with a drier free-troposphere in 2008 than in other years (consistent with Fig. 1 but using the GVRderived dataset). 


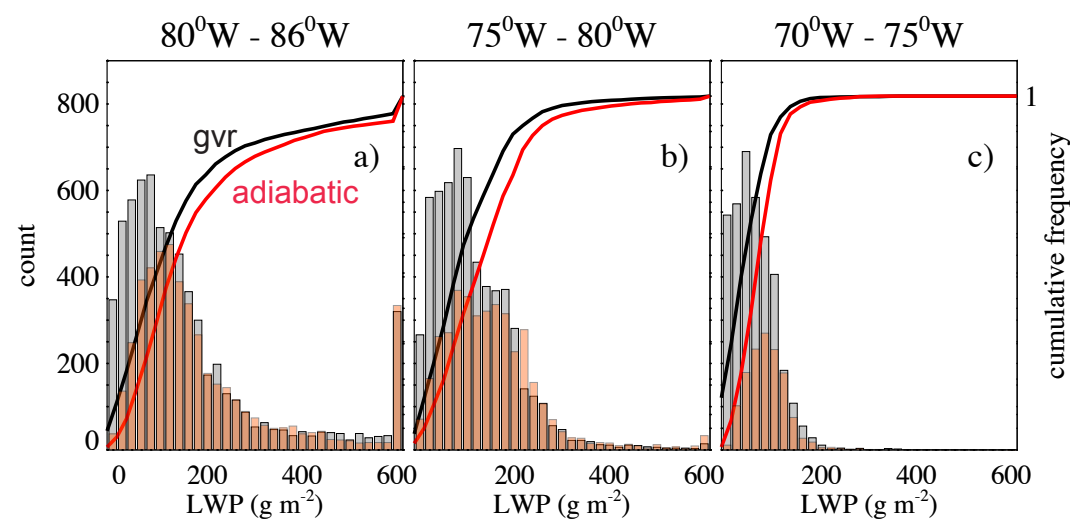

Fig. 12. Distributions of GVR-retrieved (black) and adiabatic (red) LWPs from the four research flights dedicated to a $20^{\circ} \mathrm{S}$ nighttime flight pattern out to $85^{\circ} \mathrm{W}\left(21,23,25\right.$ October and 6 November; RF 3, 4, 5 and 10) subdivided by longitude; (a) $80^{\circ} \mathrm{W}-86^{\circ} \mathrm{W}$, (b) $75^{\circ} \mathrm{W}-80^{\circ} \mathrm{W}$, and (c) $70^{\circ} \mathrm{W}-75^{\circ} \mathrm{W}$. LWP bins of $20 \mathrm{~g} \mathrm{~m}^{-2}$. The cumulative frequencies for both the GVR-retrieved (black) and adiabatic (red) LWPs correspond to the right y-axis.

\subsection{LWPs}

As shown in Fig. 9, the GVR LWP sample size for RF3 was larger $(N=5471)$ than the adiabatic sample size of 4003 , because of the GVR's ability to retrieve LWPs for thin clouds lacking radar-determined cloud tops. Most of the thin clouds occurred near the coast. This is shown by the summary statistics divided into three longitude bands for the four nighttime flights that flew along $20^{\circ} \mathrm{S}$ out to $85^{\circ} \mathrm{W}$ and back on 21 , 23 and 25 October, and 6 November (RF 3, 4, 5, and 10) in Fig. 12. These flights flew the pattern shown in Fig. 4, leaving Arica, Chile near midnight and returning at dawn. Near the coast $45 \%$ and $86 \%$ of the GVR LWPs were $<40$ and $100 \mathrm{~g} \mathrm{~m}^{-2}$ respectively. Mean \pm standard deviation (median) LWPs between $70^{\circ}-75^{\circ} \mathrm{W}$ were $67 \pm 44(61) \mathrm{g} \mathrm{m}^{-2}$. The near-midnight sampled value appears representative of the diurnal-mean satellite-derived values shown in O'Dell et al. (2008) and O'Neill et al. (2011).

Further west, the mean (median) LWPs increased to $123 \pm 87(105) \mathrm{g} \mathrm{m}^{-2}$ between $75^{\circ}-80^{\circ} \mathrm{W}$, and to $166 \pm 152$ (120) $\mathrm{g} \mathrm{m}^{-2}$ between $80^{\circ}-86^{\circ} \mathrm{W}$. Higher LWPs west of $80^{\circ} \mathrm{W}$ are consistent with deeper boundary layers and a greater propensity for precipitation (Leon et al., 2008; Zuidema et al., 2009; Bretherton et al., 2010), as well as a sampling time approaching a near-dawn diurnal maximum (Zuidema et al., 2005; O'Dell et al., 2008; O'Neill et al., 2011), but also here $23 \%$ and $50 \%$ of the GVR LWPs $<40$ and $100 \mathrm{~g} \mathrm{~m}^{-2}$. As already shown in Fig. 9, clouds with retrieved LWPs between 100 and $400 \mathrm{~g} \mathrm{~m}^{-2}$ matched adiabatically-calculated LWP values exceedingly well. This is consistent with previous results based on a smaller sample size (Zuidema et al., 2005), but not with North Atlantic observations (e.g., Pawlowska and Brenguier, 2000), and a high adiabatic fraction $\left(\mathrm{LWP}_{\text {retrieved }} / \mathrm{LWP}_{\text {adiabatic }}\right)$ may be a particular feature of the southeast Pacific stratocumulus.
The distribution of retrieved and adiabatic LWPs from the subcloud legs for all research flights except RF9 is shown in Fig. 13, subdivided by coupling. Conditions were approximately evenly divided between coupled and decoupled: $52 \%$ and $48 \%$ (Table 3). The retrieved LWP cloud fraction was $71 \%$ for the well-coupled boundary layers, versus $67 \%$ for the decoupled boundary layers, with slightly more low-LWP values retrieved within coupled conditions $(65 \%$ of the LWPs were $<100 \mathrm{~g} \mathrm{~m}^{-2}$ versus $61 \%$ for the decoupled samples). The adiabatic LWP cloud fraction, in contrast, was higher for the decoupled cases $(51 \%)$ than for the wellmixed cases $(42 \%)$. This can be explained by more radar cloud top returns for the decoupled cases because of precipitation within open cellular convection (Fig. 13c). The distributions of the GVR and adiabatic LWPs under decoupled conditions were also more similar than under coupled conditions, possibly because precipitation decoupling a boundary layer thermodynamically, may also reflect a stronger circulation that is otherwise encouraging mixing (see, e.g., Fig. 8). Overall, liquid water paths greater than $\sim 160 \mathrm{~g} \mathrm{~m}^{-2}$ were determined well by both adiabatic and millimeter-wave approaches under both coupled and decoupled conditions, and the biggest difference between the coupled and decoupled cases was in the detection of thin clouds.

The liquid water path frequencies as a function of the independently-derived cloud thickness are shown in Fig. 14. Cloud thicknesses, available for all adiabatically-calculated LWPs ( $40 \%$ of the total samples; see Table 1), were extended a further $23 \%$ by establishing the altitude of the maximum $\mathrm{dBZ}$ return as cloud top for those samples with missing cloud tops. The adiabatic LWPs are more tightly constrained by the cloud thickness values than the retrieved LWP values, as would be expected. In this figure, one-half of all the GVRretrieved LWPs correspond to clouds with recorded thicknesses $<180 \mathrm{~m}$ thick, and this excludes $15 \%$ of the clouds with retrieved LWPs and no indicated cloud top. 

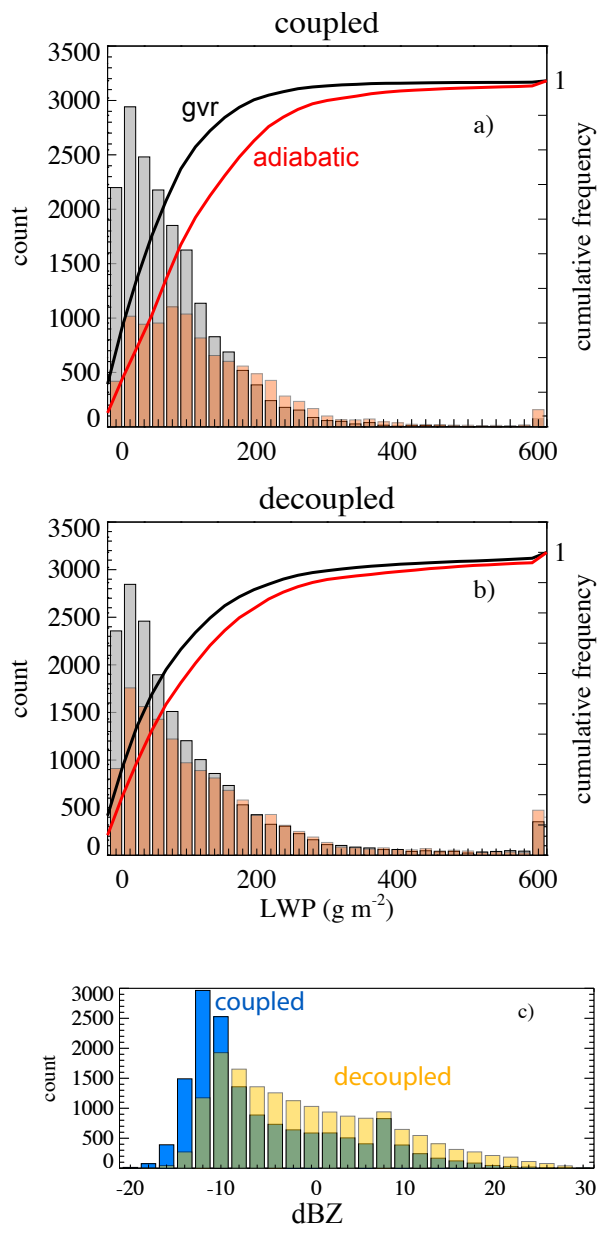

Fig. 13. Distributions of GVR-retrieved (black) and adiabatic (red) LWPs from the subcloud legs of thirteen research flights for (a) coupled $\left(Z_{\mathrm{CB}}-\mathrm{LCL}<125 \mathrm{~m}\right)$ and $(\mathbf{b})$ decoupled $\left(Z_{\mathrm{CB}}-\mathrm{LCL}>125 \mathrm{~m}\right)$ conditions. LWP bins of $20 \mathrm{~g} \mathrm{~m}^{-2}$, only samples with known cloud bases and lifting condensation levels were considered. (c) the count distributions of the column-maximum radar reflectivities for coupled and decoupled conditions.

Table 3. Number of $1 \mathrm{~Hz}$ samples contributing to the distributions shown in Fig. 13. These represent all samples from thirteen research flights with well-defined cloud bases and LCLs.

\begin{tabular}{lccc}
\hline & $\mathrm{N}$ & $\mathrm{N}_{\text {lwp }}$ & $\mathrm{N}_{\text {adlwp }}$ \\
\hline coupled & 24994 & 17817 & 10401 \\
decoupled & 26842 & 18048 & 13791 \\
total & 51836 & 35865 & 24192 \\
\hline
\end{tabular}

Figure 14 allows us to conclude that the thinner $\left(\mathrm{LWP}<100 \mathrm{~g} \mathrm{~m}^{-2}\right.$ ) clouds are also adiabatic. Histograms of the adiabatic fraction, or ratio of retrieved LWP to the adiabatically-calculated value, are shown more explicitly for coupled and decoupled boundary layers in Fig. 15. For well-

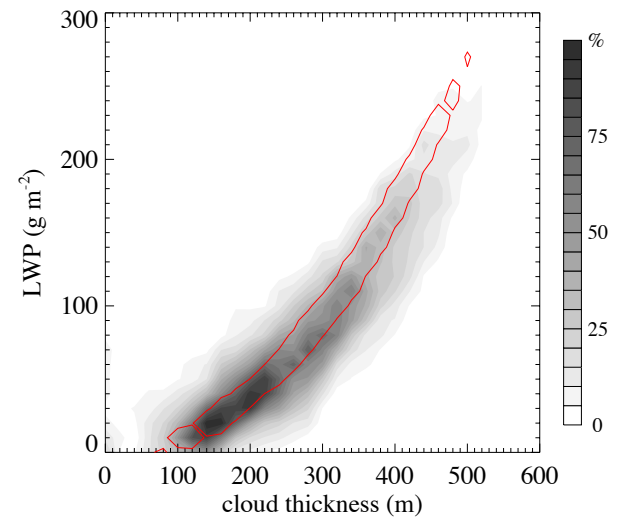

Fig. 14. Retrieved (filled grey-scale contours) and adiabatic (red contour lines) LWP relative percentages as a function of cloud thickness, based on bins of $\left(10 \mathrm{~m}, 20 \mathrm{~g} \mathrm{~m}^{-2}\right)$ in cloud thickness and LWP. Total $N_{\text {retrieved }}=32492$ and $N_{\text {adiabatic }}=24188$. 5660 LWPs were retrieved without coincident cloud thicknesses and are not included.

mixed boundary layers, the mean (median) adiabatic fraction is $0.81(0.86)$ while for decoupled boundary layers the adiabatic fraction is $0.85(0.96)$ (after disallowing adiabatic fractions $>1.0)$.

\section{Conclusions}

Brightness temperatures from a millimeter-wave radiometer on board the NCAR C-130 plane were used to retrieve abovecloud water vapor paths, and, were combined with remotelysensed cloud boundaries and in-situ thermodynamic data to retrieve liquid water paths during the sub-cloud and cloud base legs. A particular strength of the higher $183 \pm 14 \mathrm{GHz}$ frequency is the ability to retrieve low liquid water paths. The leg-mean LWP error in well-coupled conditions can originate from incorrect specification of the above-cloud WVP or boundary layer WVP (each estimated at $0.2 \mathrm{~mm}$, or $6-$ $10 \mathrm{~g} \mathrm{~m}^{-2}$ ), and a $2 \mathrm{~K}$ absolute and $0.3 \mathrm{~K}$ relative uncertainty in the GVR $T_{b}$, corresponding to $10-20 \mathrm{~g} \mathrm{~m}^{-2}$ and $2-3 \mathrm{~g} \mathrm{~m}^{-2}$, respectively (Table 2 ). Based on these numbers we conservatively estimate the absolute leg-mean LWP uncertainty to be $\sim 20 \mathrm{~g} \mathrm{~m}^{-2}$ and the relative (within-leg) uncertainty at $\sim 3 \mathrm{~g} \mathrm{~m}^{-2}$ in well-mixed conditions. In decoupled conditions, for which the boundary layer WVP specification is less certain, we estimate a higher absolute leg-mean LWP uncertainty of $25-30 \mathrm{~g} \mathrm{~m}^{-2}$. The uncertainties will be higher in heavily-precipitating conditions. Further work could be done to improve LWP retrievals in decoupled conditions within open cellular convection using all four GVR channels from the cloud-base legs.

The retrieved above-cloud water vapor paths were on par with surface-based Arctic values, further confirming the presence of a very dry troposphere in the southeast Pacific 

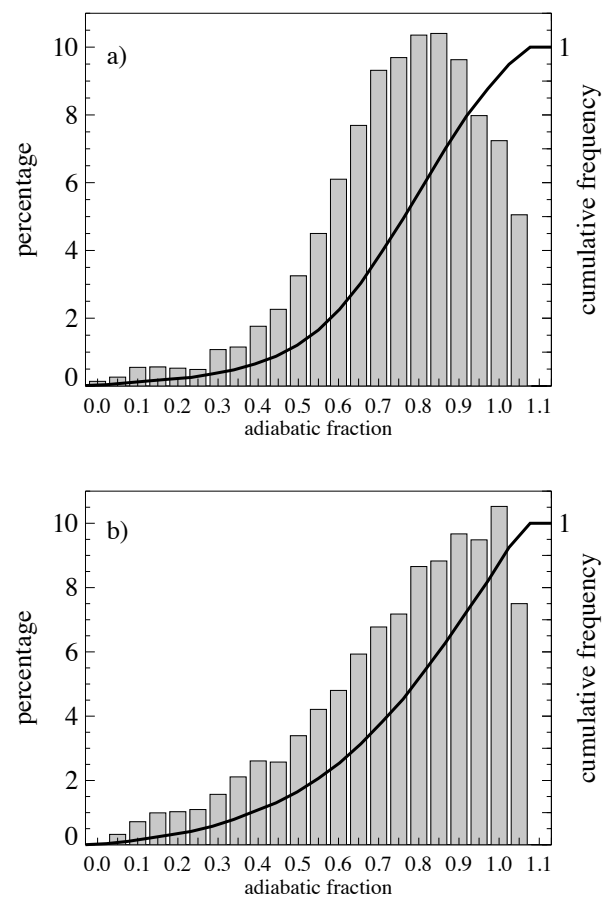

Fig. 15. Distribution of adiabatic fraction $\left(\mathrm{LWP}_{\text {retrieved }} / \mathrm{LWP}_{\text {adiabatic }}\right)$ for (a) coupled and (b) decoupled boundary layers. Only clouds with thicknesses exceeding $100 \mathrm{~m}$ were included, for a total $N$ of 22718 .

(Bretherton et al., 2010) and reinforcing the idea that a broad infrared window is available for cloud top radiative cooling. A comparison of the VOCALS retrieved free-tropospheric WVPs to radiosonde-derived values from previous years finds that the free-troposphere sampled during VOCALS was drier than in other years, with values ranging from one to two $\mathrm{mm}$ off-shore to almost one $\mathrm{cm}$ near the coast.

Clouds with LWPs $<100$ (40) $\mathrm{g} \mathrm{m}^{-2}$ composed almost two-thirds (one-third) of the entire dataset. Thin clouds were more frequent near the coast, with a mean (median) LWP of only $67(61) \mathrm{g} \mathrm{m}^{-2}$ between $70^{\circ}-75^{\circ} \mathrm{W}$. These values were measured near midnight and seem representative of their diurnal-mean (O'Dell et al., 2008; O'Neill et al., 2011). The GVR-retrieved LWPs compared well against adiabatically-derived LWPs at almost all LWP values (see Fig. 14 in particular), with $50 \%$ of the adiabatic fractions $\left(\mathrm{LWP}_{\text {retrieved }} / \mathrm{LWP}_{\text {adiabatic }}\right.$, cloud thicknesses $>100 \mathrm{~m}$ only) exceeding 0.86 . The high adiabatic fractions further support a view of southeast Pacific stratocumulus as occurring under strong, sharp inversions (e.g., Bretherton et al., 2010), with circulations strong enough to sustain cloud even in the presence of surface precipitation approaching $10-20 \mathrm{~mm}_{\text {day }}{ }^{-2}$ (Wood et al., 2011a), and with less cloud-top dilution than is observed, for example, in North Atlantic stratocumulus (e.g., Pawlowska and Brenguier, 2000).
Both boundary-layer and free-tropospheric air east of $75^{\circ} \mathrm{W}$ are likely to encounter continental aerosol (Bretherton et al., 2010). The thin, adiabatic clouds are likely to be particularly susceptible to aerosol (e.g., Petters et al., 2011; Kim et al., 2008, and references therein), which may help explain the global-maximum albedo susceptibilities derived by satellite for the southeast Pacific (Oreopoulos and Platnick, 2008). Quantitative observational estimates of the first aerosol indirect effect can vary greatly, for reasons at least partially attributable to scale and to the choice of liquid water path as a constraint (McComiskey and Feingold, 2011). The complementary airborne cloud measurements at process-level scales may help estimates of the first aerosol indirect effect made using different platforms converge for this region, and have been used to understand precipitation susceptibility for this region (Terai et al., 2011).

Data from the three cloud remote sensors have been combined into Integrated Datasets publicly available for each research flight through the NCAR Earth Observing Laboratory data archive (http://data.eol.ucar.edu/master_list/ ?project=VOCALS), with plots for each research flight available through http://www.rsmas.miami.edu/users/pzuidema. The combined datasets free users from obtaining data for the individual instruments and from some of the data processing. The VOCALS experiment was the first and last field deployment on the C-130 of the airborne GVR, but the GVR has features that recommend further aircraft deployments of similar instrumentation. It is small, easily integrated onto an aircraft platform, inexpensive, and its upward-pointing orientation is conducive for integration with other datasets including concurrent sub-cloud air sampling, as well as providing a cold space background for the LWP retrievals. The retrievals could in theory be done instantaneously through a neural net (Pazmany, 2007). The millimeter-wavelengths are not optimal for the subtropical stratocumulus region, but could be combined with lower-frequencies focused on establishing the water vapor path, such as around the $22 \mathrm{GHz}$ water vapor absorption line.

Acknowledgements. PZ acknowledges support from the NSF Large-Scale Dynamics Division under Award 0745470. We thank Walt Robinson and the VOCALS-REx PIs Rob Wood and Roberto Mechoso for their support and leadership.

Edited by: R. Wood

\section{References}

Bretherton, C. S., Uttal, T., Fairall, C., Yuter, S. E., Weller, R. A., Baumgardner, D., Comstock, K., Wood, R., and Raga, G. B.: The EPIC 2001 Stratocumulus study, B. Am. Meteorol. Soc., 85, 967-977, 2004.

Bretherton, C. S., Wood, R., George, R. C., Leon, D., Allen, G., and Zheng, X.: Southeast Pacific stratocumulus clouds, precipitation and boundary layer structure sampled along 20S dur- 
ing VOCALS-REx, Atmos. Chem. Phys., 10, 10541-10559, doi:10.5194/acp-10-10541-2010, 2010.

Buehler, S. A., Jimenez, C., Evans, K. F., Eriksson, P., Rydberg, B., Heymsfield, A. J., Stubenrauch, C. J., Lohmann, U., Emde, C., John, V. O., Sreerekha, T. R., and Davis, C. P.: A concept for a satellite mission to measure cloud ice water path, ice particle size, and cloud altitude, Q. J. Roy. Meteorol. Soc., 133, 109-128, 2007.

Cadeddu, M. P. and Turner, D. D.: Evaluation of water permittivity models from ground-based observations of cold clouds at frequencies between 23 and $170 \mathrm{GHz}$, IEEE Trans. Geosci. Remote Sens., 49, 2999-3008, doi:10.1109/TGRS.2011.2121074, 2011.

Cadeddu, M. P., Liljegren, J. C., and Pazmany, A. L.: Measurements and retrievals from a new $183-\mathrm{GHz}$ water vapor radiometer in the Arctic, IEEE Trans. Geosci. Remote Sens., 45, 2207-2215, 2007.

Cimini, D., Westwater, E. R., Gasiewski, A., Klein, M., Leuski, V. Y., and Liljegren, J.: Ground-based millimeter- and submillimeter-wave observations of low vapor and liquid water contents, IEEE Trans. Geosci. Remote Sens., 45, 2169-2180, 2007.

Cimini, D., Nasir, F., Westwater, E. R., Payne, V. H., Turner, D. D., Mlawer, E. J., Exner, M. L., and Cadeddu, M. P.: Comparison of ground-based millimeter-wave observations and simulations in the Arctic winter, IEEE Trans. Geosci. Remote Sens., 47, 30983106, 2009.

de Szoeke, S., Fairall, C. W., Wolfe, D., Bariteau, L., and Zuidema, P.: Surface flux observations on the Southeastern tropical Pacific Ocean and attribution of SST errors in coupled oceanatmosphere models, J. Climate, 23, 4152-4174, 2010.

de Szoeke, S., Yuter, S., Mechem, D., Fairall, C. W., Burleson, C., and Zuidema, P.: Observations of stratocumulus clouds and their effect on the eastern Pacific surface heat budget along $20^{\circ} \mathrm{S}, \mathrm{J}$. Climate, under review, 2011.

Hewison, T.: Aircraft validation of clear air absorption models at millimeter wavelengths (89-183 GHz, J. Geophys. Res., 111, D14303, doi:10.1029/2005JD006719, 2006.

Jones, C. R., Bretherton, C. S., and Leon, D.: Coupled vs. decoupled boundary layers in VOCALS-REx, Atmos. Chem. Phys., 11, 7143-7153, doi:10.5194/acp-11-7143-2011, 2011.

Kim, B.-G., Miller, M. A., Schwartz, S. E., Liu, Y., and Min, Q.: The role of adiabaticity in the aerosol first indirect effect, J. Geophys. Res., 113, D05210, doi:10.1029/2007JD008961, 2008.

Leon, D., Wang, Z., and Liu, D.: Climatology of drizzle in marine boundary layer clouds based on one year of data from CloudSat and CALIPSO, J. Geophys. Res., 113, D00A14, doi:10.1029/2008JD009835, 2008.

Liebe, H. J., Hufford, G. A., and Manabe, T.: A model for the complex permittivity of water at frequencies below $1 \mathrm{THz}$, Int. J. Infrared Millimeter Waves, 12, 659-675, 1991.

Liebe, H. J., Hufford, G. A., and Cotton, M. G.: Propagation modeling of moist air and suspended water/ice particles at frequencies below $1000 \mathrm{GHz}$, Atmospheric Propagation Effects through Natural and Man-Made Obscurants for Visible through MM-wave radiation, aGARD-CP-542, 3.1-3.10, 1993.

Liljegren, J. C., Boukabara, S. A., Cady-Pereiria, K., and Clough, S. A.: The effect of the half-width of the $22-\mathrm{GHz}$ water vapor line on retrievals of temperature and water vapor profiles with a twelve-channel microwave radiometer, IEEE Trans. Geosci. Remote Sens., 43, 1102-1108, 2005.
Liu, G., Shao, H., Coakley, J. A., Curry, J. A., Haggerty, J. A., and Tschudi, M. A.: Retrieval of cloud droplet size from visible and microwave radiometric measurements during INDOEX: Implication to aerosols' indirect radiative effect, J. Geophys. Res., 108, 4006, doi:10.1029/2001JD001395, 2003.

McComiskey, A. and Feingold, G.: The scale problem in quantifying aerosol indirect effects, Atmos. Chem. Phys. Discuss., 11, 26741-26789, doi:10.5194/acpd-11-26741-2011, 2011.

Miloshevich, L. M., Vomel, H., Whiteman, D., Lesht, B., Schmidlin, F., and Russo, F.: Absolute accuracy of water vapor measurements from six operational radiosonde types launched during AWEX-G and implications for AIRS validation, J. Geophys. Res., 111, D09S10, doi:10.1029/2005JD006083, 2006.

Miloshevich, L. M., Vomel, H., Whiteman, D., and Leblanc, T.: Accuracy assessment and correction of Vaisala RS92 radiosonde water vapor measurements, J. Geophys. Res., 114, D11305, doi:10.1029/2008JD011565, 2009.

O’Dell, C. W., Wentz, F. J., and Bennartz, R.: Cloud liquid water path from satellite-based passive microwave observations: a new climatology over the global oceans, J. Climate, 21, 1721-1739, 2008.

O’Neill, L. W., Wang, S., and Jiang, Q.: Satellite climatology of cloud liquid water path over the Southeast Pacific between 2002 and 2009, Atmos. Chem. Phys. Discuss., 11, 31159-31206, doi:10.5194/acpd-11-31159-2011, 2011.

Oreopoulos, L. and Platnick, S.: Radiative susceptibility of cloudy atmospheres to cloud droplet number perturbations: 2 . Global analysis from MODIS, J. Geophys. Res., 113, d14S21, doi:10.1029/2007JD009655, 2008.

Painemal, D. and Zuidema, P.: Validation of MODIS cloud effective radius and optical thickness over the Southeast Pacific during VOCALS-REx, J. Geophys. Res., 116, D24206, doi:10.1029/2011JD016155, 2011.

Pawlowska, H. and Brenguier, J.-L.: Microphysical properties of stratocumulus clouds during ACE-2, Tellus, 52B, 867-886, 2000.

Payne, V. H., Delamere, J. S., Cady-Pereira, K. E., Gamache, R., Moncet, J.-L., Mlawer, E. J., and Clough, S. A.: Air-broadened half-widths of the 22- and $183-\mathrm{GHz}$ water-vapor lines, IEEE Trans. Geosci. Rem. Sens., 46, 3601-3617, 2008.

Pazmany, A.: A compact $183 \mathrm{GHz}$ radiometer for airborne and ground-based water vapor and liquid water sensing, IEEE Trans. Geosci. Rem. Sens., 45, 2202-2206, 2007.

Petters, J. L., Harrington, J., and Clothiaux, E.: Radiativedynamical feedbacks in low liquid water path stratiform clouds, J. Atmos. Sci., under review, 2011.

Racette, P., Westwater, E., Han, Y., Gasiewski, A., Klein, M., Cimini, D., Jones, D., Manning, W., Kim, E., Wang, J., Leuski, V., and Kiedron, P.: Measurement of low amounts of precipitable water vapor using ground-based millimeterwave radiometry, J. Atmos. Ocean. Tech., 22, 317-337, 2005.

Rahn, D. A. and Garreaud, R.: Marine boundary layer over the subtropical southeast Pacific during VOCALS-REx - Part 2: Synoptic variability, Atmos. Chem. Phys., 10, 4507-4519, doi:10.5194/acp-10-4507-2010, 2010.

Rauber, R. M., Stevens, B., Ochs, H. T., Knight, C., Albrecht, B. A., Blyth, A. M., Fairall, C. W., Jensen, J. B., Lasher-Trapp, S. G., and more: Rain in Shallow Cumulus over the Ocean, B. Am. Meteorol. Soc., 88, 1912-1928, 2007. 
Rosenkranz, P. W.: Water vapor microwave continuum absorption: A comparison of measurements and models, Radio Sci., 33, 919 928, 1998.

Saide, P. E., Spak, S., Carmichael, G., Mena-Carrasco, M., Howell, S., Leon, D., Snider, J. R., Bandy, A., Collett, J., Benedict, K., de Szoeke, S., Hawkins, L., Allen, G., Crawford, I., Crosier, J., and Springston, S.: Evaluating WRF-Chem aerosol indirect effects in Southeast Pacific marine stratocumulus during VOCALS-REx, Atmos. Chem. Phys. Discuss., 11, $29723-$ 29775, doi:10.5194/acpd-11-29723-2011, 2011.

Terai, C. R., Wood, R., Leon, D., and Zuidema, P.: Does precipitation susceptibility vary with increasing cloud thickness in marine stratocumulus?, Atmos. Chem. Phys. Discuss., 11, 3337933417, doi:10.5194/acpd-11-33379-2011, 2011.

Turner, D. D. and Mlawer, E. J.: The radiative heating in underexplored bands campaigns, B. Am. Meteorol. Soc., 91, 911-923, 2010.

Turner, D. D., Clough, S. A., Liljegren, J. C., Clothiaux, E. E., Cady-Pereira, K. E., and Gaustad, K. L.: Retrieving liquid water path and precipitable water from the Atmospheric Radiation Measurement (ARM) microwave radiometers, IEEE Trans. Geosci. Remote Sens., 45, 3680-3690, 2007.

Turner, D. D., Cadeddu, M. P., Lohnert, U., Crewell, S., and Vogelmann, A. M.: Modifications to the water vapor continuum in the microwave suggested by ground-based $150-\mathrm{GHz}$ observations, IEEE Trans. Geosci. Remote Sens., 47, 3326-3337, 2009.

Vali, G., Kelly, R. D., French, J., Haimov, S., Leon, D., McIntosh, R. E., and Pazmany, A.: Finescale structure and microphysics of coastal stratus, J. Atmos. Sci., 55, 3540-3564, 1998. van Zanten, M., Stevens, B., Vali, G., and Lenschow, D. H.: Observations of drizzle in nocturnal marine stratocumulus, J. Atmos. Sci., 62, 88-106, 2005.

Wang, Z., Wechsler, P., Kuestner, W., French, J., Rodi, A., Glover, B., Burkhart, M., and Lukens, D.: Wyoming Cloud Lidar: instrument description and applications, Opt. Ex., 17, 13576-13587, 2009.

Wang, Z., French, J., Vali, G., Wechsler, P., Haimov, S., Rodi, A., Deng, M., Leon, D., Snider, J., and Peng, L.: Single aircraft integration of remote sensing and in situ sampling for the study of cloud microphysics and dynamics, B. Am. Meteorol. Soc., under review, 2011.

Wood, R., Bretherton, C., Leon, D., Clarke, A., Zuidema, P., Allen, G., and Coe, H.: An aircraft case study of the spatial transition from closed to open mesoscale cellular convection, Atmos. Chem. Phys., 11, 2341-2370, doi:10.5194/acp-11-2341-2011, 2011a.

Wood, R., Mechoso, C. R., Bretherton, C. S., Weller, R. A., Huebert, B., Straneo, F., Albrecht, B. A., Coe, H., Allen, G., Vaughan, G., Daum, P., Fairall, C., Chand, D., and more: The VAMOS Ocean-Cloud-Atmosphere-Land Study Regional Experiment (VOCALS-REx): goals, platforms, and field operations, Atmos. Chem. Phys., 11, 627-654, doi:10.5194/acp-11627-2011, 2011b.

Zuidema, P., Westwater, E. R., Fairall, C., and Hazen, D.: Shipbased liquid water path estimates in marine stratocumulus, J. Geophys. Res., 110, D20206, doi:10.1029/2005JD005833, 2005.

Zuidema, P., Painemal, D., deSzoeke, S., and Fairall, C.: Stratocumulus cloud top height estimates and their climatic implications, J. Climate, 22, 4652-4666, 2009. 